\title{
UMA FENOMENOLOGIA DA CURA ESPIRITUAL: ESTUDO DE CASO NA PESQUISA FENOMENOLÓGICA
}

\author{
Phenomenology of Spiritual Cure: A Case Study in Phenomenological Research \\ Fenomenología de la Cura Espiritual: Un Estudio de Caso en la Investigación Fenomenológica
}

CÉLIA DE MORAES

\begin{abstract}
Resumo: Este trabalho teve origem na tese de doutorado da autora, de construção e apresentação de uma metodologia para o estudo de fenômenos religiosos e espirituais. O caso descrito foi escolhido por auxiliar na compreensão da cura de um processo depressivo por via religiosa/espiritual: a revelação religiosa como processo psicológico de ampliação de consciência. Palavras-chave: Fenomenologia; Depressão; Ampliação de consciência.
\end{abstract}

Abstract: The present work is taken from the author's doctoral thesis: the construction and presentation of a methodology for the study of religious and spiritual phenomena. The case description was chosen for its value for understanding the healing of a depressive process through a religious/spiritual means: the religious revelation as a pshychological process of consciousness enlargement.

Keywords: Phenomenology; Depression; Consciousness enlargement.

Resumen: El origen de este trabajo fue de la tesis de doctorado de la autora, a partir de la construcción y presentación de una metodología para el estudio de los fenómenos religiosos y espirituales. El caso descrito fue escogido para auxiliar la comprensión de la cura de un proceso depresivo bajo la vía espiritual/religiosa: la revelación religiosa como proceso psicológico de ampliación de la conciencia.

Palabras-clave: Fenomenología; Depresión; Ampliación de la conciencia.

\section{Introdução}

O estudo da experiência vivida, consciente e subjetiva tem se mostrado mais eficaz por meio da metodologia fenomenológica (Van Kaam, 1959; Forghieri, 1993; Moraes, 1995; Amatuzzi, 1996a, 2003; Gomes, 1997; Richardson, 1999; Petrelli, 2000; Holanda, 2002; Bruns, 2003), e em especial através da entrevista fenomenológica.

Por intermédio de um processo de retro-alimentação tanto entre o sujeito percebedor (o experienciador) e o objeto percebido (a experiência) (Abreu e Silva, 1999) quanto entre entrevistado e entrevistador (Amatuzzi, 2003), esse instrumento de pesquisa busca compreender e contextualizar a experiência vivida, tomando o entrevistador o discurso do entrevistado "na sua intencionalidade própria e constitutiva, ou seja, naquilo que ele pretende efetivamente dizer" (Amatuzzi, 2003). Assim, torna-se possível ao experienciador encontrar e/ou expressar um sentido para essa experiência que lhe permita integrá-la em sua totalidade psíquica e crescer psicológica, existencial e espiritualmente, aumentando sua saúde total e seu instrumental de enfrentamento das exigências do ato de viver.

O trabalho que ora se descreve teve origem na tese de doutorado da autora, de construção e apresentação de uma metodologia para o estudo de fenômenos religiosos e espirituais e para a avaliação de experiências de ampliação de consciência. Essa pesquisa foi realizada em duas etapas. Na primeira, procedeu-se à coleta por meio da entrevista de base fenomenológica de quarenta e nove relatos de experiências religiosas/espirituais/de modificação ou ampliação de consciência, a partir de chamada divulgada pela mídia da cidade de Brasília nos termos propostos por Hardy (1979, citado em Amatuzzi, 1998b; e Hay, 1994): Alguma vez você já percebeu ou foi influenciado por uma presença ou poder diferente de seu eu cotidiano, não importando se você o chama de Deus ou não?

Na segunda etapa, foram oferecidas onze vivências em contexto grupal aos entrevistados que desejaram participar, escolhidas por seu potencial de ampliação de consciência descrito seja na bibliografia especializada, seja pelos próprios entrevistados em seus relatos. Os quatro grupos constituídos, com seis a nove pessoas cada, foram conduzidos por uma facilitadora (a pesquisadora, a mesma em todos os grupos) e um co-facilitador, e acrescidos por um observador intra-grupo que registrou comportamentos não verbais. A todos os participantes foi solicitado que relatassem por escrito percepções de sua participação ao final de cada vivência. No término de todas as vivências realizou-se uma entrevista com o intuito de avaliação, e em seguida os casos foram discutidos em conjunto pelas equipes de todos os grupos, e uma síntese fenomenológica de todo o percurso de cada participante 
foi devolvida a ele para que pudesse criticá-la, aceitando-a ou rejeitando-a.

O caso descrito no presente exemplo foi escolhido por trazer à pesquisa um dado de grande relevância para auxiliar na compreensão da cura de um processo depressivo por via religiosa/espiritual: a revelação religiosa como ampliação de consciência. A descrição fenomenológica aqui apresentada visa contribuir para essa compreensão, e não concluir por qualquer explicação, porque se trata de um diálogo muito recentemente iniciado, e muitos aspectos ainda aguardam investigação (Amatuzzi, 1996b).

Na seqüência, apresentaremos o histórico de vida e da experiência relatada pelo seu sujeito; o sentido encontrado no processo de desvelamento de sua intencionalidade, e uma discussão final segundo a fundamentação teórica de nossa pesquisa.

\section{Histórico do Caso}

Christian Theodore, 28 anos, estudante e professor, chegou à pesquisa por intermédio de um dos muitos cartazes espalhados pela Universidade de Brasília, dois dias antes das vivências começarem. Foi feita, então, uma entrevista por telefone para conhecermos o mínimo necessário de sua história de forma que pudesse participar de um grupo em iguais condições com os demais. Sua motivação para participar das vivências era "conhecer outros iguais a ele e buscar confirmações de outros 'possíveis milagres"'. Christian compareceu apenas à primeira sessão de compartilhamento, e para proteger-se de sua tendência à depressão, preferiu "não ser influenciado" na estrutura de sua fé pelos depoimentos de outras pessoas, deixando por isso o grupo. No entanto, com a análise fenomenológica do seu relato, realizado alguns dias depois, ele pôde contribuir para a compreensão do fenômeno da cura religiosa.

Antes de sua "cura", Christian vinha sofrendo há nove anos de uma depressão provocada por graves perdas afetivas. De família muito religiosa, Christian acreditava plenamente em toda a doutrina católica, na recompensa e punição imediatas de comportamentos, e viu também cair por terra toda a filosofia de vida que seguia. Sofreu uma crise de pânico e "teve um surto", e passou a ter pensamentos fixos e negativos. Assim, desde os dezoito anos tomava eventualmente medicamentos controlados, mantendo-se constantemente em terapia e vivendo grande parte de sua vida "dopado".

Isso era algo que eu não queria mais pra minha vida, era muito sofrido. $\mathrm{E}$, de fato, eu buscava nas terapias essa cura. Eu realmente era absolutamente empenhado; era mais empenhado na minha terapia do que nos meus estudos. (...) Quer dizer, eu ia pras terapias e melhorava um pouco. Era uma sensação... às vezes durava uma semana, eu precisava de uma nova terapia. (...) Sabe, era uma... existia uma emoção muito fragilizada, uma constituição... acho, na minha vida... Não sei, eu era uma pessoa muito frágil, era uma pessoa muito insegura, né? (...) Difícil me relacionar com as pessoas, muito difícil conviver...

Pra se livrar dos pensamentos persistentes, Christian tentou mudar de vida e viajou para transferir seu curso para uma universidade no exterior, e "passou mal", quase tendo outra crise de pânico. Começou lá mesmo a se relacionar com Deus "como se fosse um pai, pedindo e reclamando proteção e ajuda”. Em seguida decepcionou-se com o curso e voltou, e no dia seguinte ao seu retorno recebeu um convite de trabalho que não esperava, e que considera "uma graça de Deus", pois com ele manteve-se ocupado e longe daqueles pensamentos por uma semana, aí começando o seu aprofundamento religioso.

Realmente eu tava com uma confusão ainda interna muito grande. E eu pedi, falei pra Deus: "olha (...), se o senhor existe, se manifesta, me ajuda porque eu não sei mais o que fazer. Eu tô sozinho, eu preciso de você". Sabe, foi até uma coisa meio de briga, de pai pra filho. Cadê você que não me estende a mão, né? (...) Porque se eu voltasse e ficasse sem fazer nada; eu vou ficar de novo com essa, com essa... alimentando isso. E eu não posso. E, pedindo pra Deus, né? Pedindo pra Deus pra isso passar. E aconteceu. (...) Esse... é preciso deixar claro que esse filme, eu não tinha contato com ninguém de cinema e nem de artes... de curta metragem. Ninguém, nunca, sabe? Ele surgiu... Claro que uma pessoa me conhecia, né? Mas eu nunca fui pedir pra ninguém, nunca deixei currículo com ninguém, nunca falei que eu queria participar de nada, eu nunca soube disso. E isso aconteceu exatamente nesse momento.

Christian passou a pesquisar religiões via internet em especial o budismo, o espiritismo e o cristianismo, e passou a estudar mais a Bíblia. Logo em seguida sua mãe descobriu-se com câncer, e a família passou "a freqüentar a renovação carismática católica, procurando um milagre". Christian, muito abalado, inclusive com o sofrimento de sua mãe, resolveu "pedir 'um milagre' para ela". Aprendeu depois na Bíblia que "quando você pede pros outros, tem a doação acima de qualquer coisa, você recebe", e numa das missas carismáticas, "sentiu-se 'tocado' e curado de sua depressão".

E eu fui com muito fervor, com muito ardor, sabe, na minha fé. E essas missas são missas de cura, ah, as que a gente freqüentava. Em que se acredita que o Espírito Santo de Deus se revela e há curas nesse momento. (...) Eu tava pedindo pela cura do câncer da minha mãe e eu... e houve uma revelação de algo relacionado a depressão, de algo relacionado a isso. E... e é uma sensação... é... que parece que toca sua emoção, poderia se dizer, o coração, é... o corpo todo. É uma sensação de que, a partir daquele momento, a sua vida, de verdade, vai ser diferente. É uma sensação, é... de você... é um prazer indescritível também. (...)...um choro de emoção, você fica arrepiado. É, e você se sente absolutamente purificado nesse momento, sabe? E você não tem dúvida de que... como eu 
não tive... de que você foi curado. E foi o que aconteceu. A partir daí eu realmente não tive mais depressão. Foi nesse momento, né?

Solicitado a explicitar melhor o que entendia por "revelação", Christian explicou que não ouviu vozes nem teve visões. Ouviu do padre palavras sobre depressão com as quais se identificou profunda e totalmente, compreendendo-as como se tivessem sido ditas pra si: "foi pra mim, isso!”, e essa compreensão abalou-o e modificou-o completamente.

A partir dessa "revelação" Christian intensificou seus estudos no movimento protestante neo-pentecostal para "compreender melhor" a Bíblia e a doutrina cristã. Além disso, passou junto com seus novos companheiros a buscar viver a palavra de Deus no seu cotidiano e transformou seus relacionamentos, compreendendo e aceitando os erros e defeitos de outras pessoas, procurando dissolver crises e consertar a si mesmo, para "ser uma pessoa melhor".

Contudo, apesar de ter sua vida transformada positivamente por essa "revelação", ou "palavra de Deus" - a ponto de ter recuperado a alegria de viver e realizado o sonho de sua vida, de casar-se, ter um filho e uma família - Christian mantém-se consciente da realidade e atento para o que reconhece em si mesmo como uma "propensão à depressão”. Não se abstém da responsabilidade sobre sua saúde, e "evita algumas situações e emoções como um diabético evita açúcar”, mas não sente mais a solidão que o aterrorizava e abalava.

De fato, em sua última entrevista ele revela ter se impressionado e emocionado profundamente com o relato de uma sua companheira de grupo, sentindo imediato desejo de ajudá-la, mas ao mesmo tempo percebendo-se "incapaz de resolver o problema dela”. Por se sentir incomodado e sem desejar "carregar o problema para casa”, o que poderia, por identificação, trazer-lhe os sentimentos que sabia ter que evitar, para proteger-se Christian deixou o grupo.

\section{Sentido do Caso}

Christian coloca uma ênfase muito grande em seus processos psicoterapêuticos. Refere-se constantemente a eles e à sua última psicoterapeuta, e compara os efeitos dos tratamentos psicológicos a que se submeteu durante muitos anos com a cura espiritual que viveu. Parece-nos uma mensagem direta - como se pretendesse nos chamar a atenção, como psicólogos, para a importância muito maior que o "raciocínio espiritual” tem sobre o psicológico para as pessoas religiosas.

É preciso deixar claro que a terapia que eu fazia, ela partia de um outro raciocínio que não o religioso. E o que me curou foi o raciocínio religioso, foi o toque religioso e foi a minha maneira de entrega religiosa. Não é meu raciocínio, é minha entrega. Porque eu tava num raciocínio absolutamente racional, dentro da psicologia, como... trabalhando como, por exemplo, questões de "ah, eu preciso... é, eu... muitas vezes eu não tenho liderança porque em determinado lugar eu fico tímido por conta de que na adolescência eu tinha dificuldade de relacionar com as mulheres...”, alguma coisa assim... sabe, algumas coisas que... a partir daquela libertação não tiveram mais nenhuma importância. (...) Questões de passado, questão disso ou aquilo. Não, eu... o que me interessava eram os valores voltados pra espiritualidade, os valores... era desenvolver a minha capacidade de ser bom, a minha capacidade de ser cristão segundo Jesus Cristo ensinou e exercitar isso e combater o mal em mim. Combater as coisas ruins, combater os pensamentos ruins com a palavra de Deus, com o toque de Deus, combater os sentimentos nefastos que entre aspas são chamados de pecados, né? Pecado não é nada mais que erro, são erros, defeitos. E... e era combater isso, me aperfeiçoar enquanto ser humano.

Mais do que isso, várias vezes em sua entrevista de devolução Christian enfaticamente critica os acadêmicos ateus que "afirmam em sala de aula, sem estarem embasados, que Deus não existe, de uma forma até anti-científica". Ele se declara "preconceituoso contra os pastores ateus" que desrespeitam o aspecto humanista da ciência tentando retirar das pessoas a sua crença "sem colocar nada em troca" - e exemplifica as atrocidades do cientificismo radical com o holocausto judeu.

O sentido que sua intencionalidade encontra na experiência que viveu é o caráter religioso do caminho de aprimoramento que passa a percorrer em sua vida depois da "cura": desenvolver a capacidade de ser bom, de exercitar ser cristão segundo Jesus Cristo ensinou; combater em si mesmo o mal, os pensamentos ruins e os sentimentos nefastos chamados de "pecados" com a palavra e o toque de Deus, e se aperfeiçoar enquanto ser humano. Christian deseja "louvar a Deus e comunicar a todas as pessoas o que Ele fez em sua vida”, e para isso pede para ser chamado na pesquisa pelo seu nome verdadeiro, porque "é uma história real de alguém que não é louco nem fanático”.

\section{Discussão}

Para nós, o que interessa de perto neste caso é a descrição do processo de cura religiosa conforme vivido por Christian Theodore. Ele não ouviu vozes nem teve visões sobrenaturais - ele viveu o processo que descrevemos (Moraes, 2002) como "a percepção e absorção pela consciência de conteúdos internos ou externos a ela, no qual é envolvida a totalidade do indivíduo - corpo, emoção, razão e espírito, provocando como conseqüência a reconfiguração da própria consciência e a transformação positiva da existência como um todo" - a ampliação de consciência. 
No movimento da renovação carismática existe uma pessoa, e também no protestantismo, no caso do protestantismo o pastor, e no caso da igreja católica o padre ou uma pessoa que tenha esse trabalho, ela tem... serve de instrumento para o Espírito Santo, então ela recebe revelações, e ela disse, e eu me identifiquei, recebi uma dessas revelações nesse momento pra mim, quer dizer, me identifiquei. Foi uma revelação pra mim, nesse momento, dessa forma. Não uma revelação de vozes ou de visões, não. (...) Eu me identifiquei. Mas esse identifiquei, literalmente, né, “é pra mim isso”. Tem pra outras pessoas também, mas foi pra mim.

Sua experiência de ampliação de consciência teve, assim, um contexto religioso - caracterizando-se como uma experiência transcendente religiosa. Por ter uma família e uma história religiosas, uma busca por Deus em todas as religióes, uma experiência anterior de graça alcançada ou oração respondida e uma freqüência à Igreja, Christian pediu, e pôde receber do que acreditava profundamente ser um "instrumento do Espírito Santo" a resposta que precisava para livrar-se da depressão.

Abriu-se e entregou-se plenamente de corpo, emoção, intelecto e espírito à "palavra de Deus", que funcionou naquele momento como um catalizador de sua totalidade - a "convergência dinâmica de todos os 'campos' (geo-biológico, psico-emocional, sócio-ambiental e sacrotranscendental) presentes", atualizando o seu "impulso natural humano em direção à completeza, à plenitude, à unicidade" (Ribeiro, 1994).

Benson $(1975,1984,1998)$ enfatiza o potencial que a inclusão das crenças pessoais tem no processo de abertura e cura dos indivíduos doentes. Christian só pôde abrir-se porque a mensagem provinha de uma fonte que ele acreditava em seu mais íntimo como sendo a verdade. Assim, Christian "encontrou a totalidade da palavra, o "insight fenomenológico"; permitiu a "chegada dessa totalidade à consciência", que se tornou consciência emocionada (Ribeiro, 1994), e dessa maneira atingiu a cura - "a restauração do equilíbrio do seu organismo através da reorganização de suas partes”. Ao incorporar a nova totalidade ao organismo, a consciência emocionada transformou-se em consciência ampliada.

Segundo nossa dissertação de mestrado (Moraes, 1995), Christian passou por várias das etapas básicas do processo de ampliação de consciência, traduzidas pelas categorias (1) antecedentes - a disciplina de busca de ajuda para livrar-se da angústia e da depressão: as terapias, as orações constantes e a freqüência à igreja; (2) contexto imediato - o desejo premente de ajudar a mãe doente; (3) fatores, ou condições para a ampliação - a disciplina, a "palavra de Deus" como catalisadora e a entrega; (4) sensação física de prazer em ser "tocado"; (5) sensações emocionais e afetivas, de prazer indescritível, de choro e arrepio e a sensação de ter sido "purificado"; (6) outras características - a certeza de ter sido curado; (14) avaliação da experiência como "o impossível", "o milagre", "uma graça de Deus”; (15) sentimento retrospectivo de graça, de "maravilha”; (16) conseqüências no retorno do prazer de viver, na realização do sonho de toda a sua vida e na transformação de si mesmo e dos relacionamentos com outras pessoas; (20) ocorrência de duas experiências, a oração atendida e a cura; (21) conhecimento - a busca de aprofundamento nos estudos da Bíblia no neo-pentecostalismo e no estudo de outras religiões via internet; e (22) expressão - a dificuldade de relatar uma experiência indescritível.

Nossa proposta aqui é oferecer uma descrição de como algumas experiências de revelação - que resultam em cura de sintomas patológicos - podem ocorrer. Outras revelações religiosas podem ocorrer de maneira diferente da revelação de Christian Theodore. Apresentamos nossas conclusões como parte de um diálogo que se pretende continuado, visto que a experiência de Christian conforme vivida por ele é muito mais rica do que aqui esboçado, e passível de ser discutida de muitas outras maneiras.

\section{Referências Bibliográficas}

Abreu e Silva, N. N. (1999). A psicologia descritiva de Franz Brentano. Brasília: Manuscrito não publicado.

Amatuzzi, M. M. (1996a). Apontamentos acerca da pesquisa fenomenológica, Estudos de Psicologia, 13 (1), 5-10.

Amatuzzi, M. M. (1996b). A experiência religiosa: uma leitura de Martin Buber, Estudos de Psicologia; 13 (3), 63-70.

Amatuzzi, M. M. (1998b). Experiência religiosa: estudando depoimentos, Estudos de Psicologia,15, (2), 3-27.

Amatuzzi, M. M. (2003). Pesquisa fenomenológica em psicologia, In M. A. T. Bruns \& A. F. Holanda (Orgs). Psicologia e pesquisa fenomenológica: reflexões e perspectivas (pp.1522). Campinas: Alínea.

Benson, H. (1975). A resposta do relaxamento. Rio de Janeiro: Record.

Benson, H. (1984). Transcendendo o relaxamento. Rio de Janeiro: Record.

Benson, H. (1998). Medicina espiritual. Rio de Janeiro: Campus.

Bruns, M. A. T. (2003). A redução fenomenológica em Husserl e a possibilidade de superar impasses da dicotomia subjetividade-objetividade, In M. A. T. Bruns Psicologia e pesquisa fenomenológica: reflexões e perspectivas (pp.57-65. Campinas: Alínea.

Forghieri, Y. C. (1993). Psicologia fenomenológica. São Paulo: Pioneira.

Gomes, W. B. (1997). A entrevista fenomenológica e o estudo da experiência consciente, Psicologia USP [online], vol. 8, no. 2, [citado 2008-06-10], pp. 305-336. Disponível em: http:// www.scielo.br/scielo.php?script=sci_arttext\&pid $=$ S0103$65641997000200015 \& \operatorname{lng}=\mathrm{es} \& \mathrm{nrm}=$ iso 
Hay, D. (1994). The biology of god: what is the current status of hardy's hypotesis?, The International Journal for the Psychology of Religion, 4, (1), 1-23.

Holanda, A. F. (2002). O resgate da fenomenologia de Husserl e a pesquisa em psicologia. Tese de Doutorado em Psicologia, Pontifícia Universidade Católica de Campinas, Campinas.

Moraes, C. C. (1995). O êxtase: uma abordagem do ponto de vista da psicologia clínica e das religiões. Dissertação de Mestrado, Universidade de Brasília, Brasília.

Moraes, C. C. (2002). Trabalhando com os fenômenos religiosos e espirituais: uma proposta metodológica para avaliação da experiência de ampliação de consciência no processo grupal. Tese de Doutorado em Psicologia, Universidade de Brasília, Brasília.

Petrelli, R. (2000). Fenomenologia: teoria, método e prática. Goiânia: Editora da UCG.

Ribeiro, J. P. (1994). O processo grupal. São Paulo: Summus Editora.

Richardson, A. (1999). Subjective experience: its conceptual status, method of investigation, and psychological significance, The Journal of Psychology, 133,(5), 469-485.

Van Kaam, A. L. (1959). Phenomenal analysis: exemplified by a study of the experience of 'really feeling understood', Journal of Individual Psychology, 15, 66-72.

Celia de Moraes é Psicóloga Clínica, Gestalt-Terapeuta, Mestre e Doutora em Psicologia pela Universidade de Brasília. Email: <ccdmoraes@ gmail.com>

Recebido em 13.07.08

Aceito em 12.08.09 